\title{
Assessment of the Phylogenetic Affiliation Levels of Water Mite (Acari, Hydrachnidia) Species with the Elemental Analysis Method
}

\author{
Ferruh Aşçi ${ }^{1}$, Mustafa Uçar², Şaban Kabak¹, Muhlis Özkan ${ }^{3}$ \\ ${ }^{1}$ Molecular Biology and Genetics Department, Afyon Kocatepe University, Afyonkarahisar, Turkey \\ ${ }^{2}$ Chemistry Department, Afyon Kocatepe University, Afyonkarahisar, Turkey \\ ${ }^{3}$ Education Faculty, Uludağ University, Bursa, Turkey \\ Email: $\underline{f \text { asci@aku.edu.tr }}$
}

Received 5 May 2015; accepted 22 June 2015; published 26 June 2015

Copyright (C) 2015 by authors and Scientific Research Publishing Inc.

This work is licensed under the Creative Commons Attribution International License (CC BY).

http://creativecommons.org/licenses/by/4.0/

(c) (i) Open Access

\begin{abstract}
10 different species of water mites which are Georgella helvetica, Eylais extendens, Hydrachna globose, Hydrachna prosifera, Hydrachna skorikowi, Hydrodroma despiciens, Hydryphantes dispar, Limnesia fulgida, Eylais setosa, Hydryphantes flexuosus were used in this study. The total masses of these species were measured as $\mathrm{mg}$ with the use of an elemental analyzer to calculate the percentage of the organic components of their structures. The achieved values were assessed separately for each species and element with the interpolation method. Out of these organic elements, the amount of $C$ with an approximately value of $50 \%$ was the highest for all species while the amounts of $S$ which was approximately $1 \%$ was determined as the lowest for almost all species. The observed values were discussed in terms of the systematic of water mites.
\end{abstract}

Keywords

Water Mites, Acari, Hydrachnidia, Elemental Analyzer, Interpolation Method

\section{Introduction}

Water mites, also known as the Hydracarina, Hydrachnidia or Hydrachnellae, are a group of nine superfamilies and more than 40 families from the prostigmatan Cohort Parasitengona. Although other taxa of parasitengone mites have species with semi-aquatic habits (e.g. the Johnstonianidae), only the Hydracarina are truly subaquatic. There are approximately 5000 named species of water mites [1]; however, as water mites of Africa, Asia, and much of South America have not been thoroughly studied it is likely that this is a major underestimation of their 
true number. They live in all types of freshwater bodies, from tree holes to hot springs to deep lakes and torrential waterfalls and some have also ventured into oceans [2].

Water Mites related to numerous scientific studies have been conducted so far. These studies until recently are often systematic and taxonomy in the field seen [2]-[4]. However, in recent years, water mites with made in ecological and genetic studies have been seen [5]-[7]. Genetic studies into water mites are still in their early stages. It is clear from the number of articles which is limited [8]-[10]. This is the first time that the ratios of the types of organic compounds have been determined and evaluated by interpolation at the species level.

The objective of this study was to assess whether there is an affiliation between the element amounts of the polyphyletic water mites in this study and the phylogenetic similarities determined previously by a systematic approach with a view on structural similarities by various researchers. 10 species belonging to 5 Hydracnidia families (Eylaidae, Hydrachnidae, Hydryphantidae, Hydrodromidae Limnesiidae) were analyzed for C, N, H and $\mathrm{S}$ in this study. The purpose of this determination which qualifies as a preliminary study is to highlight whether or not there was significance on a categorical level in terms of phylogenetic approaches.

Besides the classical measurement method, this method could be used as a method to help make the determination, which may be encountered in the future and thus contribute to the solution of problems of measurement. The sample type which has been defined as the weight percent of organic compounds and from which of 8 were determined as reference samples, other 2 samples given as a test sample.

\section{Materials and Methods}

Water mites were collected in June 2012 from Karamık Lake (Afyonkarahisar) and identified in the laboratory after being washed in distilled water. The samples were dried after the water mites belonging to the same species were weighted on a sensitive scale. Mettler Toledo MX5 microbalance is connected to the elemental analyzer to weigh the sample used for analysis. The readability of the balance is $1 \mu \mathrm{g}$ and repeatability is $0.8-0.9 \mu \mathrm{g}$.

Carbon (C), hydrogen $(\mathrm{H})$, nitrogen $(\mathrm{N})$ and sulfur $(\mathrm{S})$ contents of water mite species were determined by using a Vario EL III universal CHNS-O elemental analyzer. Principle of analysis, the basic principle of quantitative CHNS-O analysis is high temperature combustion of organic and many inorganic solid or liquid samples. The gaseous combustion products are purified, separated into their various components and analyzed with a suitable detector such as TCD (thermal conductivity dedector).

Interpolation is a method of constructing new data points within the range of a discrete set of known data points. Interpolation is an available technique for a number of data points, obtained by either sampling or experimentation, which represent the values of a function for a limited number of values of the independent variable. The value of that function for an intermediate value of the independent variable is required to interpolate, which is achieved by curve fitting or regression analysis. In this paper, curve fitting was used to obtain the function of the variables. By using interpolation, relation between weight of samples and $\mathrm{C}, \mathrm{N}, \mathrm{H}, \mathrm{S}$ weights was investigated for different species of water mites.

\section{Results}

The analyzed species were selected from types which are available in all zoogeographical zones. While the Hydryphantidae from the Palearctic zone were represented with 27 species, the other families (Eylaidae: 2, Hydrachnidae: 1, Hydrodromidae: 1, Limnesiidae: 1) had less representation [3] [11].

Table 1 reveals that high amounts of carbon were measured in Hydrachna globosa (51.690\%) while the nitrogen levels were high for Hydrachna skorikowi (13.060\%), hydrogen was high in Hydrachna processifera (6.938\%) and sulfur amounts were high in Eylais extendens (1.333\%) whereas the least amount of carbon was found in Hydrachna skorikowi (47.050\%), nitrogen in Georgella helvetica (8.647\%), hydrogen amounts in Eylais extendens (6.112\%) and sulfur in Hydrachna processifera $(0.787 \%)$. It is evident that the difference between the low and high values of the measured carbon amounts are close to each other compared to the average rate $[\mathrm{x}=54.713(51.960-47.050)](8.4 \%)$ and this is followed by hydrogen $[\mathrm{x}=6.467(6.938-6.112)]$ $(12.772 \%)$ while this proportional difference is most pronounced with nitrogen [x $=10.428$ (13.060 - 8.647)] (42.328\%) and sulfur [x $=0.949(1.333-0.787)](57.534 \%)$.

The sequence of the C, N, H and S on a genus level is as follows; Hydrodromidae: 57.577\% Hydryphantidae: 66.355\% Eylaidae: 66.936\% Hydrachnidae: 68.124\% Limnesiidae: 70.48\%. Total mass and mass and percentage of C, $\mathrm{N} \mathrm{H}$ and $\mathrm{S}$ values of different species of water mites measured by element analyzer are given in Table 1. 
Table 1. Mass, percentage and weight of C, N, H and S of samples.

\begin{tabular}{ccccccccccc}
\hline Sample & Species & Mass $(\mathbf{m g})$ & $\mathbf{\%} \mathbf{C}$ & $\mathbf{m}_{\mathbf{C}}(\mathbf{m g})$ & $\mathbf{\%} \mathbf{N}$ & $\mathbf{m}_{\mathbf{N}}(\mathbf{m g})$ & $\mathbf{\%} \mathbf{H}$ & $\mathbf{m}_{\mathbf{H}}(\mathbf{m g})$ & $\mathbf{\%} \mathbf{S}$ & $\mathbf{m}_{\mathbf{S}}(\mathbf{m g})$ \\
\hline R1 & Georgella helvetica & 0.8800 & 50.230 & 0.4420 & 8.647 & 0.0760 & 6.263 & 0.0551 & 1.152 & 0.0101 \\
R2 & Eylais extendens & 0.8840 & 49.760 & 0.4398 & 9.526 & 0.0842 & 6.112 & 0.0540 & 1.333 & 0.0117 \\
R3 & Hydrachna globosa & 3.4750 & 51.690 & 1.7962 & 9.225 & 0.3205 & 6.328 & 0.2198 & 0.952 & 0.0330 \\
R4 & Hydrachna prosifera & 3.1080 & 50.620 & 1.5732 & 10.410 & 0.3235 & 6.938 & 0.2156 & 0.787 & 0.0244 \\
R5 & Hydrachna skorikowi & 3.8510 & 47.050 & 1.8118 & 13.060 & 0.5029 & 6.427 & 0.2475 & 0.886 & 0.0341 \\
R6 & Hydrodroma despiciens & 2.3545 & 48.157 & 1.1338 & 11.647 & 0.2742 & 6.871 & 0.1617 & 0.902 & 0.0212 \\
R7 & Hydryphantes dispar & 3.2023 & 49.496 & 1.5850 & 10.623 & 0.3401 & 6.321 & 0.2024 & 0.815 & 0.0260 \\
R8 & Limnesia fulgida & 2.9273 & 51.236 & 1.4998 & 12.084 & 0.3537 & 6.370 & 0.1864 & 0.790 & 0.0231 \\
T1 & Eylais setosa & 1.8710 & 50.340 & 0.9418 & 9.202 & 0.1721 & 6.536 & 0.1222 & 1.063 & 0.0198 \\
T2 & Hydryphantes flexuosus & 3.2045 & 48.328 & 1.5486 & 9.863 & 0.3160 & 6.513 & 0.2087 & 0.815 & 0.0261 \\
\hline
\end{tabular}

The samples are divided into two groups, reference samples and test samples as shown in Table 1 R1-8 and T1-2, respectively. Reference samples have been used to calculate C, N, S and H weight of the test samples by using interpolation methods. According to the interpolation method the function of the reference samples has been obtained from Figures 1-4 and is given in Table 2 and Figure 5.

The C, N, H and S weights of samples were calculated by using the percentage of $\mathrm{C}$ and the total mass of samples (Table 1). Sample mass-Carbon weight of samples graph is given in Figure 1 and the carbon weight equation for reference samples has been obtained as “ $\mathrm{y}=0.4924 \mathrm{x}+0.0124$ ”. The $\mathrm{R}^{2}$ value of the graph is 0.9913 and shows a correlation of the mass and carbon weight of samples. $\mathrm{N}$ weight to total mass (Figure 2), $\mathrm{H}$ weight to total mass (Figure 3) and S weight to total mass (Figure 4) graphs plotted in a similar way and correlation factor and weight equation have been obtained as 0.9194 and “ $\mathrm{y}=0.1203 \mathrm{x}+0.9194$ ”, 0.9905 and “ $\mathrm{y}=$ $0.0651 x+0.0004$ ”, 0.9417 and “ $y=0.0074 x+0.0037$ ”, respectively.

Calculated C, N, H and S weight of test samples according to function of Figures 1-4 are given in Table 2, experimental values and the difference between calculated and experimental weights are also given in Table 2.

\section{Discussion}

The sequence established according to the amounts of $\mathrm{C}, \mathrm{N}, \mathrm{H}$ and $\mathrm{S}$ on a genus level comprised as a result of using more than twenty characteristics does not comply with the cladistic listing in the form of Eylaidae-Hydrachnidae-Hydryphantidae-Hydrodromidae-Limnesiidae. Given the ratio of measured elements, it is evident that only Limnesiidae maintains its position, the sequences of the others change while Eylaidae is observed in phylogenetically higher groups because of the ratio of these elements.

It is a known fact that Eylaoidae is close to Hydrovolzoidae within Hydrachnidia. However, many of the structural characteristics found in the other supra genus (Hydryphantoidae, Lebetoidae, Hygrobatoidae) are not evident. Therefore, the problems in the systematics of the superfamily continue to date and the differentiation which started in the early Mesozoic age continues [3] [12]. There is wide acceptance in favor of the argument that during different geological ages the Hydracnidia which were essentially polyphyletic transposed from a terrestrial life into aquatic environments and that the initial settlement areas were primarily springs and later extended to other aquatic environments and that this proliferation and differentiation continues [13]. Therefore, it is argued that it would be beneficial to review the evolutionary assumptions regarding phylogenetic affiliations as well as implement various molecular methods [12] [14]-[16].

We believe it is beneficial to query whether the major differences between the low and high values of sulfur and nitrogen amounts (N: 42.328\%; S: 57.534\%) are related to the chitinization of the relevant species. In such a situation, the structure of the body cover and the other hairs and plate structures which complement it become prominent. Hydracnidia are known to feature a combination of hard and more flexibly structured chitinized structures. The body cover and particularly the chitin plates and subsequently the external skeleton are further 


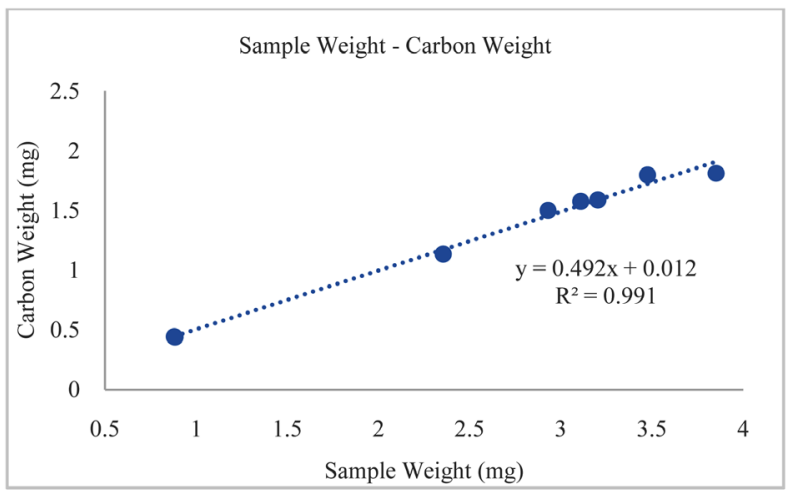

Figure 1. Graph of the carbon weight to mass of reference samples.

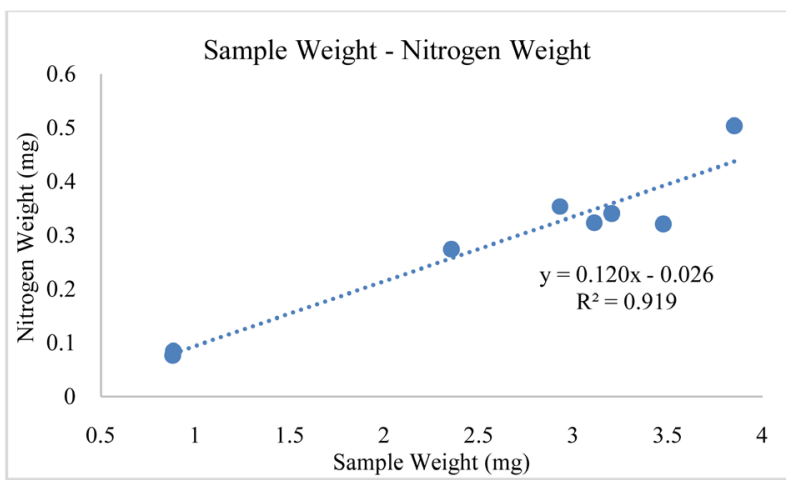

Figure 2. Graph of the nitrogen weight to mass of reference samples.

Sample Weight - Hydrogen Weight

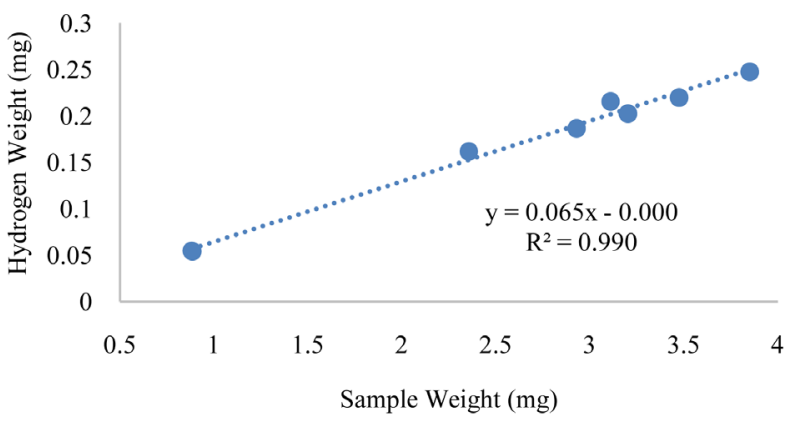

Figure 3. Graph of the hydrogen weight to mass of reference samples.

Table 2. Calculated, experimental weight and difference between these values of test samples.

\begin{tabular}{|c|c|c|c|c|c|}
\hline & Test Sample & & Calculated & Experimental & \% Difference \\
\hline \multirow{4}{*}{$\mathrm{T} 1$} & \multirow{4}{*}{ Eylais setosa } & C Weight (mg) & 0.93368 & 0.94186 & 0.868452 \\
\hline & & N Weight (mg) & 0.198381 & 0.17217 & 15.2241 \\
\hline & & H Weight (mg) & 0.121402 & 0.12229 & 0.726061 \\
\hline & & S Weight (mg) & 0.017545 & 0.019889 & 11.7834 \\
\hline \multirow{4}{*}{$\mathrm{T} 2$} & \multirow{4}{*}{ Hydryphantes flexuosus } & C Weight (mg) & 1.590296 & 1.54867 & 2.68784 \\
\hline & & N Weight (mg) & 0.358801 & 0.31606 & 13.5232 \\
\hline & & H Weight (mg) & 0.208213 & 0.20871 & 0.238153 \\
\hline & & S Weight (mg) & 0.27413 & 0.026117 & 4.96343 \\
\hline
\end{tabular}


Sample Weight - Sulfur Weight

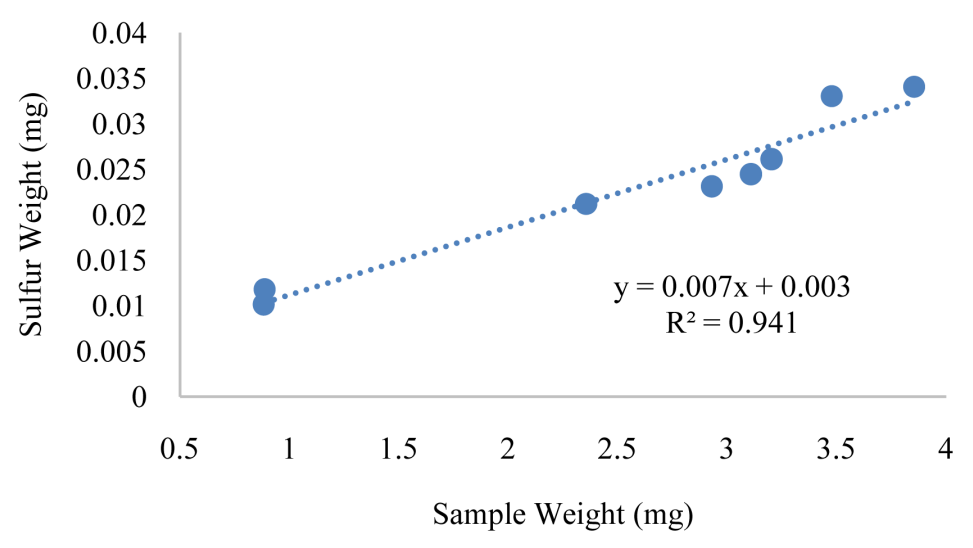

Figure 4. Graph of the sulfur weight to mass of reference samples.

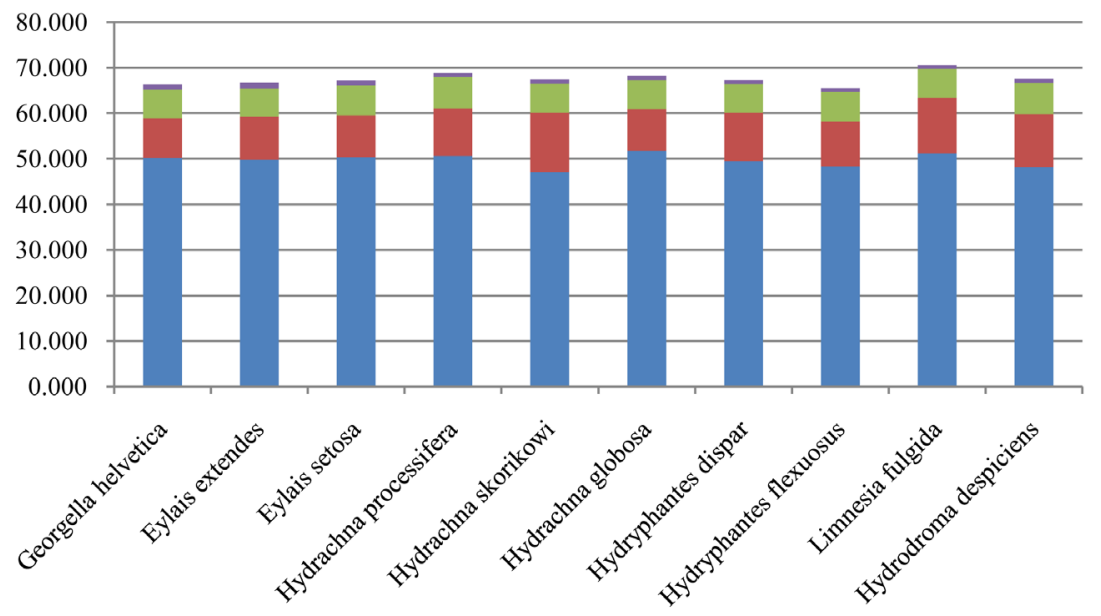

Figure 5. Percentage and weight of C, N, H and S of samples.

hardened with the addition of $\mathrm{CaCO}_{3}$ into the chitin (N-asetil-D-glukoz-2-amin) $\left(\mathrm{C}_{8} \mathrm{H}_{13} \mathrm{O}_{5} \mathrm{~N}\right)_{\mathrm{n}}$ structure comprising of a polysaccharide consisting of soft and covalent $\beta-1,4$ ligaments when pure [17]. Hydrachna skorikowi (13.060\%) and Limnesia fulgida (12.840\%) have higher amounts of nitrogen compared to the other species. We believe that this determination does not contradict expectations.

The relation between total mass and the weight of some elements was determined in terms of the achieved values in this paper. Furthermore, different species of water mites were used to determine whether or not there was a significant difference between species.

The percentage of Carbon in all samples is around $50 \%$ which shows that there is no difference between the species of water mites. Similarly, $\mathrm{N}$ percentage is around $10 \%, \mathrm{H}$ percentage is around $6 \%$, and $\mathrm{S}$ percentage is around $1 \%$ in all samples. All values of elemental analysis show that there is no remarkable difference between used species of water mites. This can be seen also in the linearity of Figures 1-4. Therefore, elemental analysis is not a usable method in the systematic of these species of water mites.

Interpolation method gives important results for all samples. One can determine $\mathrm{C}, \mathrm{N}, \mathrm{H}$ and $\mathrm{S}$ weight of any sample by using functions which are given in Figures 1-4, with insignificant errors; the average value of errors is $6.25 \%$.

\section{Acknowledgements}

Special thanks to Dr. M. Poyraz from Chemistry Dept. for experimental works and Dr. İ.H. Sarpün from Physics Dept. for statistical works. 


\section{References}

[1] Smith, I.M. and Cook, D.R. (1991) Ecology and Classification of North American Freshwater Invertebrates. Academic Press, San Diego, 523-592.

[2] Cook, D.R. (1974) Water Mite Genera and Subgenera. American Entomological Institute, 21, 860.

[3] Di Sabatino, A., Smit, H., Gwerecke, R., Golschmidt, T., Matsumoto, N. and Cicolani, B. (2008) Global Diversty of Water Mites (Acari, Hydrachnidia, Arachnidia) in Fresh Water. Hydrobiologia, 595, 303-315. http://dx.doi.org/10.1007/s10750-007-9025-1

[4] Smith, H. and Hammen van der, H. (2000) Atlas van de Nederlandse watermijten (Acari: Hydrachnidia). Nederlandse Faunistische Mededelingen, 13, 3-272.

[5] Więcek, M., Martin, P. and Gąbka, M. (2013) Distribution Patterns and Environmental Correlates of Water Mites (Hydrachnidia, Acari) in Peatland Microhabitats. Experimental Applied Acarology, 61, 147-160. http://dx.doi.org/10.1007/s10493-013-9692-8

[6] Di Sabatino, A., Boggero, A., Miccoli, F.P. and Cicolani, B. (2004) Diversity, Distribution and Ecology of Water Mites (Acari: Hydrachnidia and Halacaridae) in High Alpine Lakes. Experimental Applied Acarology, 34, 199-210. http://dx.doi.org/10.1023/B:APPA.0000045251.44202.58

[7] Miccoli, F.P., Lombardo, P. and Cicolani, B. (2013) Indicator Value of Lotic Water Mites (Acari: Hydrachnidia) and Their Use in Macroinvertebrate-Based Indices for Water Quality Assessment Purposes. Knowledge and Management Aquatic Ecosystems, 411, 8. http://dx.doi.org/10.1051/kmae/2013075

[8] Edwards, D.D. and Labhart, M. (2000) Genetic Differences among Host-Associated Populations of Water Mites (Acari: Unionicolidae: Unionicola): Allozyme Variation Supports Morphological Differentiation. Journal of Parasitology, 86, 1008-1011. http://dx.doi.org/10.1645/0022-3395(2000)086[1008:GDAHAP]2.0.CO;2

[9] Onrat, S.T., Aşçi, F. and Ozkan, M. (2006) A Cytogenetics Study of Hydrodroma Despiciens (Müller, 1776) (Acari: Hydrachnellae: Hydrodromidae). Genetics and Molecular Research, 30, 342-349.

[10] Asadi, M., Hinomotob, N., Sabooric, A. and Javan-Nikkhahc, M. (2012) Genetic Diversity in Mitochondrial Cytochrome c Oxidase Subunit I Sequences of the Water Mite Hygrobates fluviatilis (Acari: Hydrachnidia: Hygrobatidae). International Journal of Acarology, 38, 96-100. http://dx.doi.org/10.1080/01647954.2011.633558

[11] Gerecke, R. (2003) Water Mites of the Genus Atractides Koch, 1837 (Acari: Parasitengona: Hygrobatidae) in the Western Palaearctic Region: A Revision. Zoological Journal of the Linnean Society, 138, 141-378. http://dx.doi.org/10.1046/j.1096-3642.06-0.00051.x

[12] Abe, H. (2000) Phylogeny and Evolution. Journal of Acarology Society Japan, 9, 1-13. http://dx.doi.org/10.2300/acari.9.1

[13] Bader, R.E. (1954) Ueberdie Herstell ungeinesagglutinierenden Serumsgegen die Rund form von Shigella sonnei miteinem Stamm der Gattung Pseudomonae. Zeitschrift für Hygiene und Infektionskrankheiten, 140, 450-456. http://dx.doi.org/10.1007/BF02184857

[14] Witte, H. and Döring, D. (1999) Canalized Patways of Change and Constraints in the Evolution of Reproductive Modes of Micro Arthropods. Experimental Applied Acarology, 23, 181-216. http://dx.doi.org/10.1023/A:1006062813800

[15] Witte, H. and Olomski, R. (1999) The Evolutionary Transformation of Functional Systems in the Parasitengona. Acarology IX: Symposia, Ohio Biological Survey, Colombus, 125-136.

[16] Harvey, M.S. (2008) The Australien Water Mites. A Guide to Families and Genera. Monogr. Invertebrata Hydrobiologia, 595, 303-315.

[17] Cziak, G., Langer, H. and Ziegler, H. (1984) Biologie. Springer-Verlag, Berlin Heidelberg, 944. 